\title{
ANTIMICROBIAL RESISTANCE AND PCR-RIBOTYPING OF SHIGELLA RESPONSIBLE FOR FOODBORNE OUTBREAKS OCCURRED IN SOUTHERN BRAZIL
}

\author{
Cheila Minéia Daniel de Paula ${ }^{*}$, Mercedes Passos Geimba ${ }^{2}$, Patrícia Heidrich do Amaral ${ }^{1}$, Eduardo Cesar Tondo ${ }^{1}$
}

${ }^{1}$ Universidade Federal do Rio Grande do Sul, Porto Alegre, RS, Brasil; ${ }^{2}$ Universidade Católica do Rio Grande do Sul, Porto Alegre, RS, Brasil.

Submitted: April 08, 2009; Returned to authors for corrections: April 04, 2010; Approved: June 21, 2010.

\begin{abstract}
Little information about Shigella responsible for foodborne shigellosis is available in Brazil. The present study aimed to investigate the antimicrobial resistance and PCR-ribotyping patterns of Shigella isolates responsible for foodborne outbreaks occurred in Rio Grande do Sul State (RS), Southern Brazil in the period between 2003 and 2007. Shigella strains $(n=152)$ were isolated from foods and fecal samples of victims of shigellosis outbreaks investigated by the Surveillance Service. Identification of the strains at specie level indicated that $71.1 \%$ of them were S. flexneri, $21.5 \%$ S. sonnei, and $0.7 \%$ S. dysenteriae. Ten strains $(6.7 \%)$ were identified only as Shigella spp. An increasing occurrence of S. sonnei was observed after 2004. Most of the strains were resistant to streptomycin (88.6\%), followed by ampicillin (84.6\%), and sulfamethoxazole/trimethoprim $(80.5 \%)$. Resistant strains belonged to 73 patterns, and pattern A (resistance to ampicillin, sulfamethoxazole/trimethoprim, tetracycline, streptomycin, chloramphenicol, and intermediate resistance to kanamycin) grouped the largest number of isolates $(\mathrm{n}=36)$. PCR-ribotyping identified three banding patterns (SH1, SH2, and SH3). SH1 grouped all S. flexneri and SH2 grouped all S. sonnei. The S. dysenteriae strain belonged to group SH3. According to the results, several Shigella isolates shared the same PCR-rybotyping banding pattern and the same resistance profile, suggesting that closely related strains were responsible for the outbreaks. However, other molecular typing methods need to be applied to confirm the clonal relationship of these isolates.
\end{abstract}

Key words: Shigellosis, Shigella, antimicrobial, PCR-Ribotyping, RS/Brazil.

\section{INTRODUCTION}

Many microorganisms can cause foodborne diseases; however, Shigella has been identified as one of the most important agent of diarrhea by World Health Organization (WHO) (44). Kotloff et al. (22) reported that annual cases of shigellosis is around 165 million, with more than 1.1 million deaths. According to Silva et al. (40), shigellosis is currently an important health problem around the world, occurring predominantly in children younger than five years old, mainly in developing countries. Shigellosis is caused by Shigella spp., including Shigella dysenteriae, Shigella flexneri, Shigella boydii and Shigella sonnei (23). Among Shigella species, S. flexneri and $S$. sonnei are the most prevalent in the developing and industrialized countries, respectively $(33,38)$.

Shigella is generally transmitted by contaminated water,

*Corresponding Author. Mailing address: Universidade Federal do Rio Grande do Sul, Brasil.; E-mail: cheilapaula@ yahoo.com.br 
uncooked food, and by contact with infected individuals (26, 44). The low infective dose, as few as 200 viable organisms, facilitates the direct transmission (person to person spreading). Humans and few primates are the only known reservoirs of Shigella (37, 44), and transmission among humans are common. According to Navia and Gascón (26) foodborne outbreaks occur due to the clonal propagation of one or few Shigella strains.

Shigella invades the local epithelium of the colon (large intestine) in a stepwise format: entry into epithelial cells, intracellular multiplication, intra-and intercellular spreading, and killing of the host cell (32). Gastroenteritis caused by Shigella spp. is usually self-limited, although shigellosis is one of the few enteric infections in which antimicrobial agents are prescribed to reduce the duration of the illness and the period of Shigella excretion after symptoms subside. Consequently, increasing resistance against the most used antimicrobials has been observed (18).

In Brazil there are few reports on foodborne shigellosis, probably attributed to the fact that no current regulation requires the investigation of Shigella in water or foods. However, according to the Brazilian Health Minister Central Laboratory in Rio Grande do Sul (RS) State (FEPPS/LACEN/RS), this microorganism is frequently isolated from stools of patients with diarrhea in foodborne outbreaks in Southern Brazil.

Shigella has been characterized by diverse methods, including antibiotic resistance and genotyping methods in Brazil (35) and in other countries as Chile (16), Iran (37), and Spain (15). The determination of antibiotic resistance of Shigella has been carried out, since it can rapidly provide information about resistant strains (3) and also can serve as a preliminary typing method. However, due to the low discrimination power of the antimicrobial resistance typing, DNA based methods has been recommended. Among them, PCR-ribotyping has been applied with success because it is rapid to perform, presents relatively low cost and also has been used to type enteric pathogens such as Salmonella $(19,27,28)$.

Based on this, the objective of the present study was to characterize Shigella isolates responsible for foodborne outbreaks occurred in the Southern Brazil for their antimicrobial resistance patterns and PCR-ribotypes.

\section{MATERIAL AND METHODS}

\section{Bacterial strains identification and serotyping}

Shigella isolates: Shigella isolates used in this study were obtained from stool samples of shigellosis patients and from foods involved in outbreaks occurred in different localities of Rio Grande do Sul State, Southern Brazil. Shigella isolates from foods were collected in a 12-month period, between August 2007 and August 2008. Samples of suspected foods were collected during epidemiological investigation of foodborne outbreaks carried out by the Sanitary Surveillance Division of Rio Grande do Sul. Based on symptoms and epidemiological data, the foodborne outbreaks were suspected to be salmonellosis or shigellosis. Samples were tested for compliance to the Brazilian Federal Regulation RDC 12/2001 (2) in the Central Laboratory of Rio Grande do Sul (FEPPS/IPB/LACEN/RS) following APHA methods (1). Before disposal, 1200 plates of XLD agar (Oxoid Ltd., Hampshire, England) and SS Agar (Oxoid Ltd., Hampshire, England) used for detection of Salmonella, were sent to the Food Microbiology Laboratory of the Food Science and Technology Institute of Federal University of Rio Grande do Sul (ICTA/UFRGS) for investigation of Shigella spp. Typical colonies of Shigella were selected (217), transferred to BHI Agar (Oxoid Ltd., Hampshire, England), and submitted to the following tests for identification: motility, hydrogen sulphide production, indole production, use of citrate, glucose, sucrose, and lactose fermentation in TSI agar (Oxoid Ltd., Hampshire, England), and lysine decarboxylase in LIA (Difco, Detroit, Michigan). After identification, Shigella isolates were confirmed by serological tests (14), using antisera supplied by Probac do Brasil (Sao Paulo, Brazil).

Other 149 Shigella isolates were obtained from fecal samples of patients presenting nausea, vomiting, and diarrhea, between January 2003 and December 2007 (Table 1). After 
identification of the strains by the Bacteriology Section of FEPPS/IPB/LACEN/RS, they were sent to the Food Microbiology Laboratory of ICTA/UFRGS for evaluation of the antimicrobial resistance and PCR-ribotyping.

\section{Antimicrobial resistance testing}

Shigella isolates were analyzed for susceptibility to nine antimicrobial agents by the disc diffusion method according to the Clinical and Laboratory Standards Institute (7). The antimicrobials and their respective concentrations ( $\mu \mathrm{g} / \mathrm{disc})$ were: ampicillin (AMP), 10; tetracycline (T), 30; gentamicin (GEN), 10; nalidixic acid (NAL), 30; chloramphenicol (C), 30; streptomycin (S), 10; ciprofloxacin (CIP), 5; supplied by Laborclin (Parana, Pinhais, Brazil) and sulfamethoxazole/trimethoprim (SXT), 25; kanamycin (K), 30. The disks were supplied by Oxoid (Hampshire, United Kingdom), and Escherichia coli ATCC 25922 used as a reference strain for internal control. For the purpose of typing, resistance patterns were determined, creating a numerical code based on the antibiotic resistance of each isolate. Resistance was classified as 1 , intermediate resistance as 2 , and full sensitivity as 3 (42).

\section{PCR-Ribotyping}

Extraction of DNA: the genomic DNA was extracted by heat treatment, as described below: one colony of each isolate was inoculated in $3 \mathrm{ml}$ of BHI broth (Oxoid Ltd., Hampshire, England) and incubated overnight at $37^{\circ} \mathrm{C}$. After incubation, 1 $\mathrm{ml}$ suspensions of bacterial cells were centrifuged at $5000 \mathrm{xg}$ for 4 minutes in a microcentrifuge Eppendorf model 5415C, at room temperature. The supernatant was discarded and the pellet was suspended in $1 \mathrm{ml}$ of TE $(10 \mathrm{mM}$ Tris $\mathrm{HCl}, \mathrm{pH} 8.0$, $1 \mathrm{mM}$ EDA $\mathrm{pH}$ 8.0). This step was repeated twice. The pellet was suspended in $100 \mu \mathrm{l}$ of TE, kept in a thermal block for 10 minutes at $95^{\circ} \mathrm{C}$, and then centrifuged at $14000 \mathrm{xg}$ for 20 seconds. The supernatant was used in the PCR reactions, as described below.

PCR amplification: the primers used in the test were proposed by Jensen and Hubner (20) and were specific for the amplification of the spacer region between $16 \mathrm{~S}$ and 23S rRNA genes. The sequences of the primers were the following: 5' CAA GGC ATC CAC CGT GT 3' and 5' GTG AAG TCG TAA CAA GG 3'. Each set of PCR reactions included a control without DNA template. The PCR-Ribotyping mixture $(25 \mu \mathrm{l})$ consisted of $2.5 \mu \mathrm{l}$ of reaction buffer $\left(100 \mathrm{mmol} \mathrm{l}^{-1}\right.$ Tris $\mathrm{HCl}, 750 \mathrm{mmol} \mathrm{l}^{-1} \mathrm{KCl} \mathrm{pH} \mathrm{8.8),} 0.4 \mu \mathrm{l}$ of $10 \mathrm{mmol}^{-1} \mathrm{dNTPs}(5$ mmol $1^{-1}$ of each dATP, dCTP, dGTP, and dTTP), $1 \mu 1$ of 50 mmol 1 ${ }^{-1} \mathrm{MgCl}_{2}, 2 \mu \mathrm{l}$ of each primer (20 $\left.\rho \mathrm{mol}\right), 0.4 \mathrm{U}$ of Taq DNA Polymerase $2 \mathrm{U} / \mu \mathrm{l}$ (Invitrogen, Sao Paulo, Brazil), 14.9 $\mu 1$ sterile ultrapure water, and $2 \mu \mathrm{l}$ DNA. The program used for the amplification was as follows: one initial cycle of $94^{\circ} \mathrm{C}$ for 2 minutes, followed by 25 cycles of $94^{\circ} \mathrm{C}$ for $15 \mathrm{~s}, 55^{\circ} \mathrm{C}$ for 4 minutes and $72^{\circ} \mathrm{C}$ for 1 minute, and a final extension step of $72^{\circ} \mathrm{C}$ for 30 minutes. Amplifications were carried out on a Minicycler (MJ Research, Watertown, MA, USA) and $10 \mu 1$ of amplified products were resolved by electrophoresis in $2.0 \%$ agarose gel in TBE buffer. The gels were stained with ethidium bromide, and visualized under UV light.

Strains with different electrophoretic DNA banding patterns were tested at least twice to evaluate the reproducibility of the method. E. coli ATCC 25922, S. aureus ATCC 25923, E. coli O157:H7, S. Cholerasuis ATCC 10708, and $S$. Enteritidis 3091/05 strains were used to evaluate the discriminatory power of the method. S. Enteritidis 3091/05 was used as a control strain in all PCR-Ribotyping amplifications. The amplified banding patterns were visually compared and ascribed to the same PCR-Ribotyping when their patterns were identical.

\section{RESULTS AND DISCUSSION}

\section{Isolation of Shigella}

Three Shigella strains were isolated from food samples involved in foodborne outbreaks occurred in RS. Strains were identified as S. flexneri $(\mathrm{n}=2)$ and $S$. sonnei $(\mathrm{n}=1)$, and were isolated from plates considered negative for the presence of Salmonella by the Official Laboratory of RS (FEPPS/IPB/LACEN/RS). As the investigation of Shigella in 
foods is not mandatory in Brazil and no Salmonella was found in these food samples, the etiologic agent of those outbreaks could have been considered unidentified. According to Carmo et al. (4), the etiologic agent of $80 \%$ of the 3.737 notified foodborne outbreaks occurred in Brazil could not be identified. This high percentage of unidentified causal agents can be attributed to different factors as: lack of food samples to be analyzed, insufficient sensitivity of the analytical methods, emerging pathogens not investigated, and the lack of official mandatory regulation for certain food pathogens, including Shigella.

Shigella is phylogenetically related to Salmonella, and both are related to Escherichia coli (17). Based on this fact and on the lack of appropriate detection methods, the diagnosis of shigellosis is very difficult. Currently, there are no specific selective media for the isolation of Shigella from food samples. In the present work, the isolation of Shigella was possible using methods for Salmonella recommended by the American Public Health Association (24) and FDA (14). Recently Warren et al. (43) published a review about methods for detection of Shigella in foods, and cited such methodologies. The authors also emphasized the need for an appropriate conventional culture protocol specifically designed for the detection of Shigella in foods.

\section{Human fecal samples}

The Shigella isolates obtained from human fecal samples (149) belonged to specie S. flexneri (71.1\%), followed by $S$. sonnei $(21.5 \%)$. Only one isolate $(0.7 \%)$ was identified as $S$. dysenteriae. Ten isolates (6.7\%) were identified only as Shigella spp. These results are similar to those obtained in Brazil by Peirano et al. (35), who studied 296 Shigella strains isolated from human fecal samples in the Laboratory for Cholera and Enteric Diseases (NRLCED) of Fundação Instituto Oswaldo Cruz, Rio de Janeiro, Brazil, during the period of 1999 to 2004. The majority of the strains $(52.7 \%)$ were $S$. flexneri, and $44.2 \%$ were S. sonnei, $2.3 \%$ were S. boydii, and only two $(0.6 \%)$ were $S$. dysenteriae. Silva et al. (40) reported that Shigella was the fourth causative agent of diarrhea in 877 infants assisted by a public hospital in Rondonia, in the Western Amazon region, Brazil, and among 25 isolates identified to species level, $72 \%$ were S. flexneri, $12 \%$ S. sonnei, $12 \%$ S. boydii, and $4 \%$ S. dysenteriae.

Similar results were also reported in other countries. Savadkoohi and Kacho (38), in Iran, observed that among 260 Shigella strains isolated from stool samples, $70 \%$ were $S$. flexneri and $30 \%$ were S. sonnei. In counterpart, in the United States, according to the CDC, there is a prevalence of $S$. sonnei. Between 1999 and 2002, among 1,598 isolates obtained in the National Antimicrobial Resistance Monitoring System for Enteric Bacteria (NARMS), and identified to species level, 1,278 (80 \%) were S. sonnei, 295 (18\%) were S. flexneri (16\%), $18(1 \%)$ were S. boydii, and $7(0.4 \%)$ were $S$. dysenteriae (41).

Besides varying according to the geographical area, being S. sonnei the prevalent specie (>80\%) in developed countries and $S$. flexneri the most common specie in developing countries (23), the prevalence of Shigella species varies over time. According to the results of the present study, in 2003 only S. flexneri was isolated in RS. However, between 2004 and 2007 , the occurrence of S. sonnei increased from $17.9 \%$ in 2004 to $43.5 \%$ in 2007. Consequently, the incidence of $S$. flexneri decreased expressively: in 2003 all isolates were identified as S. flexneri, but in 2007 they accounted for only $47.8 \%$ of the outbreaks (Table 1 ).

Table 1. Etiologic agents of shigellosis occurred in Rio Grande do Sul, Brazil, during the period of 2003 to 2007.

\begin{tabular}{cccc}
\hline Year & Species & Number of cases & Percent (\%)* \\
\hline \multirow{2}{*}{2003} & S. sonnei & 0 & 0.00 \\
& S. flexneri & 6 & 100.00 \\
\hline \multirow{2}{*}{2004} & S. sonnei & 10 & 17.86 \\
& S. flexneri & 46 & 82.14 \\
\hline \multirow{2}{*}{2005} & S. sonnei & 8 & 27.59 \\
& S. flexneri & 21 & 72.41 \\
\hline \multirow{2}{*}{2006} & S. sonnei & 4 & 11.43 \\
& S. flexneri & 22 & 62.86 \\
& S. dysenteriae & 1 & 2.86 \\
& Shigella spp. & 8 & 22.86 \\
\hline \multirow{2}{*}{2007} & S. sonnei & 10 & 43.48 \\
& S. flexneri & 11 & 47.83 \\
& Shigella spp. & 2 & 8.70 \\
\hline
\end{tabular}


According to Chuang, et al. (8), between 250 and 500 cases/year of shigellosis were identified in Taiwan from 1995 to 2000 . The majority were caused by $S$. flexneri and $S$. sonnei, which accounted for $73.3 \%$ and $26.5 \%$ of the total strains isolated, respectively. However, from 2001 to 2003, S. sonnei replaced $S$. flexneri as the predominant specie in central Taiwan (44).

According to Table 2, Shigella was isolated most frequently from children under 5 years of age, accounting for $40.7 \%$ of the isolates. People aged 5-19 years were involved in approximately $19.0 \%$ of the cases, and those aged 20-59 years were identified in $16.1 \%$ of the cases. The overall distribution of Shigella isolates by gender was similar, with females accounting for $44.3 \%$ of the isolates and male for $49.0 \%$.

In United States, the Shigella Surveillance: Annual Summary 2005 (5) reported that $30.0 \%$ of the cases of Shigellosis affected children under 5 years of age, $34.3 \%$ of them persons aged 5-19 years, and 26.6 \% persons aged 20-59.
Differences on gender were not verified.

\section{Antimicrobial resistance testing}

The antimicrobial resistance of 152 isolates of Shigella is shown in Table 3. The highest resistance percentages occurred against streptomycin (88.6\%), ampicillin (84.6\%), and sulfamethoxazole/trimethoprim $(80.5 \%)$, and the highest frequency of intermediate resistance was displayed against kanamycin $(61.7 \%)$. The majority of the isolates was sensitive to ciprofloxacin (96.6\%), nalidixic acid (89.3\%), and gentamicin (83.2\%). Savadkoohi and Kacho (38) also reported high resistance rates to sulfamethaxazole/trimetoprim $(73.8 \%)$ and to ampicillin (73.8\%) in Shigella isolated from children with acute diarrhea in the North of Iran. The sensitivity to ciprofloxacin was similar to our results $(97.3 \%)$. Silva et al. (40) studied Shigella spp. isolated from a public hospital in Rondonia/Brazil, and demonstrated high levels of resistance to sulfamethoxazol/trimethoprim and ampicillin.

Table 2. Distribution of cases of foodborne shigellosis occurred in Rio Grande do Sul between 2003 and 2007, according to age, gender and species of Shigella.

\begin{tabular}{|c|c|c|c|c|c|}
\hline Age Group & Species & Female & Male & Unknown & Total \\
\hline \multirow{3}{*}{$<1$ Year } & S. flexneri & 7 & 5 & 0 & 12 \\
\hline & S. sonnei & 0 & 1 & 0 & 1 \\
\hline & Shigella spp. & 0 & 1 & 0 & 1 \\
\hline \multirow{4}{*}{1 to 4 Years } & S. flexneri & 16 & 17 & 0 & 33 \\
\hline & S. sonnei & 2 & 5 & 0 & 7 \\
\hline & S. desynteriae & 0 & 1 & 0 & 1 \\
\hline & Shigella spp. & 1 & 4 & 0 & 5 \\
\hline \multirow{3}{*}{5 to 9 Years } & S. flexneri & 6 & 6 & 0 & 12 \\
\hline & S. sonnei & 4 & 4 & 0 & 8 \\
\hline & Shigella spp. & 0 & 1 & 0 & 1 \\
\hline \multirow{2}{*}{10 to 19 Years } & S. flexneri & 3 & 4 & 0 & 7 \\
\hline & S. sonnei & 1 & 0 & 0 & 1 \\
\hline \multirow{3}{*}{20 to 29 Years } & S. flexneri & 3 & 3 & 0 & 6 \\
\hline & S. sonnei & 2 & 1 & 0 & 3 \\
\hline & Shigella spp. & 1 & 0 & 0 & 1 \\
\hline 30 to 39 Years & S. flexneri & 3 & 3 & 0 & 6 \\
\hline 40 to 49 Years & S. flexneri & 2 & 3 & 0 & 5 \\
\hline \multirow{3}{*}{50 to 59 Years } & S. flexneri & 0 & 1 & 0 & 1 \\
\hline & S. sonnei & 1 & 0 & 0 & 1 \\
\hline & Shigella spp. & 1 & 0 & 0 & 1 \\
\hline \multirow{2}{*}{60 to 69 Years } & S. flexneri & 1 & 1 & 0 & 2 \\
\hline & S. sonnei & 1 & 0 & 0 & 1 \\
\hline 70 to 79 Years & S. sonnei & 1 & 0 & 0 & 1 \\
\hline \multirow{3}{*}{ Unknown Age } & S. flexneri & 8 & 8 & 6 & 22 \\
\hline & S. sonnei & 1 & 5 & 3 & 9 \\
\hline & Shigella spp. & 1 & 0 & 0 & 1 \\
\hline tal & & & & & 149 \\
\hline
\end{tabular}


Table 3. Antimicrobial resistance of Shigella spp. isolated from stools associated with foodborne outbreaks occurred in Rio Grande do Sul, Brazil, between 2003 and 2007

\begin{tabular}{|c|c|c|c|c|c|c|c|c|c|}
\hline \multicolumn{10}{|c|}{ Antimicrobial resistance (\%) of Shigella spp. } \\
\hline & AMP & $\mathrm{T}$ & GEN & NAL & CIP & $\mathrm{C}$ & $\mathrm{S}$ & SXT & $\mathrm{K}$ \\
\hline Sensitive & 12.08 & 26.84 & 83.22 & 89.26 & 96.64 & 42.28 & 7.38 & 16.78 & 22.82 \\
\hline Intermediate resistance & 3.36 & 12.75 & 6.04 & 8.06 & 3.36 & 2.68 & 4.03 & 2.68 & 61.74 \\
\hline Resistance & 84.56 & 60.40 & 10.74 & 2.68 & 0.00 & 55.04 & 88.59 & 80.53 & 15.44 \\
\hline
\end{tabular}

ampicillin (AMP); tetracycline (T); gentamicin (GEN); nalidixic acid (NAL); ciprofloxacin (CIP); chloramphenicol (C); streptomycin (S); sulfamethoxazole/trimethoprim (SXT); kanamycin $(\mathrm{K})$.

In a study conducted in northeastern Brazil, Sidrim et al. (39) reported that 26 strains of $S$. flexneri were resistant to sulfamethoxazole/trimethoprim, ampicillin and tetracycline. Resistances to chloramphenicol and gentamicin were verified in $84.6 \%$ and $7.6 \%$ of the isolates, respectively, and all strains were sensitive to nalidixic acid and ciprofloxacin.

Both S. flexneri and S. sonnei showed high percentages of resistance to ampicillin, streptomycin, sulfamethoxazole/ trimethoprim, but there were differences in resistance to other antimicrobial agents. More strains of S. flexneri were resistant to tetracycline $(79.2 \%)$ and chloramphenicol $(73.6 \%)$ than $S$. sonnei (3.13\% and $6.25 \%$ ) (data not shown). In United States, the National Antimicrobial Resistance Monitoring System for Enteric Bacteria (NARMS), also reported that $S$. flexneri and $S$. sonnei presented differences in resistance against antimicrobial agents. In the NARMS Human Isolates Final Report, 2005, resistance to tetracycline and chloramphenicol was higher among S. flexneri while $S$. sonnei isolates showed a higher resistance to streptomycin and sulfamethoxazole/trimethoprim. The percentage of isolates with no detected resistance was low in S. sonnei (4.4\%) and S. flexneri (5.8\%) (6).

Based on the antimicrobial resistance of the isolates, they were grouped in 73 patterns (Table 4). Nine patterns grouped $44.1 \%$ of the isolates.

The results indicated that $96.7 \%$ of the strains (147 isolates) were resistant to at least one drug and only two isolates were sensitive to all drugs tested. Multiple resistance, i.e. resistance to two or more drugs, was observed in 137 isolates $(90.2 \%)$ and, among them, $82.2 \%$ were resistant to three or more antibiotics. Food isolates were resistant only to gentamicin and presented intermediate resistance to chloramphenicol, tetracycline, and sulfamethoxazole/ trimethoprim, belonging to the patterns G, H, and I (Table 4). The three food isolates belonged to three different and unique patterns, suggesting that they differ from the fecal stool isolates.

Table 4. Most expressive antimicrobial resistance patterns of Shigella isolated from fecal stool samples and from foods associated with foodborne shigellosis occurred in Rio Grande do Sul, Brazil.

\begin{tabular}{ccccc}
\hline Pattern & Phenotype & $\begin{array}{c}\text { Number of } \\
\text { isolates for } \\
\text { each pattern }\end{array}$ & \% & $\begin{array}{c}\text { Numerical } \\
\text { code }\end{array}$ \\
\hline A & $\begin{array}{c}\text { AMP, SXT, T, S, C } \\
\text { (I:K) }\end{array}$ & 36 & 23.68 & 111131233 \\
B & AMP, SXT, T, S (I:K) & 9 & 5.92 & 111133233 \\
C & AMP, SXT, T, S, C, & 5 & 3.28 & 111131133 \\
D & AMP, SXT, T, S, C & 5 & 3.28 & 111131333 \\
E & AMP, SXT, S (I:K) & 5 & 3.28 & 113133233 \\
F & AMP, SXT, S & 4 & 2.63 & 113133333 \\
G* & GEN, (T:I), (C:I) & 1 & 0.66 & 321332333 \\
H* & $\quad$ (T:I), (C:I) & 1 & 0.66 & 323332333 \\
I* & (T:I), (SXT:I) & 1 & 0.66 & 323333323 \\
\hline $\begin{array}{l}\text { * food samples. ampicillin (AMP); tetracycline (T); gentamicin (GEN); } \\
\text { nalidixic acid (NAL); ciprofloxacin (CIP); chloramphenicol (C); streptomycin } \\
\text { (S); sulfamethoxazole/trimethoprim (SXT); kanamycin (K). }\end{array}$
\end{tabular}


Resistance profile A contained 36 S. flexneri isolates, all resistant to ampicillin, sulfamethoxazole/trimethoprim, tetracycline, streptomycin, chloramphenicol, and intermediately resistant to kanamycin. Profile B grouped nine S. flexneri isolates (5.9\%), differing from the profile A only by the sensitivity to chloramphenicol. Profile C and D grouped five $S$. flexneri isolates each, and profile E grouped five $S$. sonnei isolates. The remaining isolates $(\mathrm{n}=85)$ were grouped in further 65 patterns, and accounted for $55.9 \%$ of the tested isolates. The most multi-resistant were one $S$. flexneri isolate that presented resistance to ampicillin, sulfamethoxazole/ trimethoprim, tetracycline, streptomycin, chloramphenicol, and kanamycin (profile $\mathrm{M}$ ), and two $S$. flexneri isolates that presented resistance to ampicillin, sulfamethoxazole/ trimethoprim, tetracycline, streptomycin, chloramphenicol, kanamycin, and gentamicin (profile $\mathrm{N}$ ).

Several studies have reported the involvement of drug resistant $S$. sonnei and $S$. flexneri in foodborne diseases. For example, among 392 Shigella isolates obtained from stool specimens of persons with acute diarrhea in southern Trinidad, during 1997-2006, 75\% of the S. sonnei isolates were resistant to all antibiotics tested (ampicillin, tetracycline, sulphamethoxazole/trimethoprim, amoxicillin-clavulanic acid, cefuroxime, chloramphenicol, ciprofloxacin, aztreonam, and gentamicin) (30). In Calcutta, during a 4-year period (2001 to 2004), all S. flexneri isolates obtained from hospitalized children with diarrhea between 2001 and 2004, were resistant to ampicillin, cotrimoxazole, tetracycline, nalidixic acid and fluoroquinolones (33).

Over a 12-year period, 68 Shigella isolates (31 S. sonnei, 30 S. flexneri, 4 S. dysenteriae, and 3 S. boydii) were collected in a French University Hospital from the stools of patients with recent history of travel to various parts of the world particularly Africa and tested for drug resistance. These isolates were often resistant to streptomycin, spectinomycin, trimethoprim, tetracycline, and sulfonamides, resistant to ampicillin and chloramphenicol (66 to $84 \%$ ), or resistant to nalidixic acid. Multi-resistance was verified in $87 \%$ of the isolates, and a total of 13 antibiotic resistance patterns were identified (13).
In Brazil, a study conducted over a period of 24 months aiming to assess the resistance of enteropathogens isolated from children with diarrhea in Rondonia (Western Amazon region, Brazil) indicated high frequency of strains resistant to sulfamethoxazole/trimethoprim, ampicillin, amicacin, penicillin and cotrimoxazol. Eighteen S. flexneri isolates displayed resistance to multiple antibiotics, as well as a low frequency of resistance to nalidixic acid and quinolones (ciprofloxacin and norfloxacin) (40). Other study, comprising 62 Shigella (47 S. flexneri, and 15 S. sonnei) isolates selected from fecal samples and tested in Laboratory for Cholera and Enteric Diseases (NRLCED) of Fundação Instituto Oswaldo Cruz, Rio de Janeiro, Brazil, during 1999-2003, indicated that all isolates were susceptible to nalidixic acid, ciprofloxacin and gentamicin. All but one (cefalothin resistant) was cephalosporin-susceptible. A total of eight antimicrobial resistance profiles were identified. The profile AMP, SMX, TMP, SPT, STR, TET, CHL was the most common and grouped 38 S. flexneri isolates. Profile SMX, TMP, SPT, STR, TET contained 12 S. sonnei isolates (34).

Emerging patterns of antimicrobial resistance of Salmonella and Shigella species are a serious concern in several parts of the world where enteric and typhoid fever and other forms of salmonellosis and shigellosis are endemic. The emergence of multi-resistant strains has important clinical and public health implications for populations at risk, for this reason surveillance is continuously needed (25). The emergence of resistant Shigella spp. strains, resulting in increased mortality, presents a major threat to disease control, particularly in less developed countries where antibiotics are frequently prescribed on an empirical basis. According to Dromigny et al. (12) regular studies should be conducted in order to monitor drug resistance and contribute to bacterial diarrhea control efforts.

\section{PCR-ribotyping}

The PCR-ribotyping used in the study was able to discriminate Shigella species and other bacterial genera since samples containing DNA of S. flexneri, S. sonnei, S. aureus 
ATCC 25923, S. Cholerasuis ATCC 10708, and S. Enteritidis 3091/05 yielded distinct banding patterns. Interestingly, Shigella species presented the same banding as $E$. coli ATCC 25922 and E. coli O157:H7. According to Coimbra et al. (9) Shigella spp. (except S. boydii serotype 13) and Escherichia coli constitute a single DNA relatedness group, and on a strict scientific basis, the Shigella species should be considered as E. coli clones. Corroborating this similarity, Shigella spp. and enteroinvasive E. coli (EIEC) have been considered responsible for shigellosis in humans (32).

In this study, the 152 Shigella isolates (149 fecal stools analysis, presented three banding patterns, designated $\mathrm{SH} 1, \mathrm{SH} 2$, and

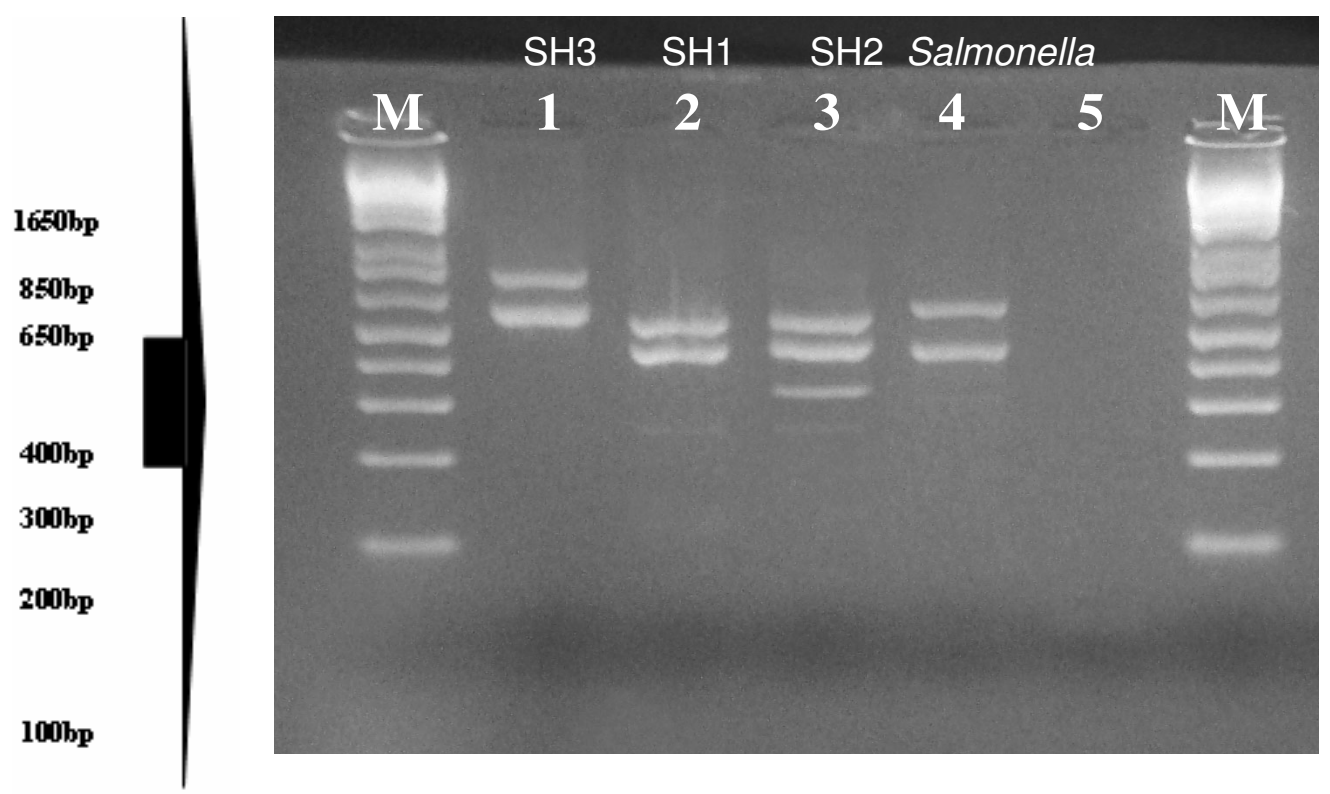

Figure 1. PCR-ribotyping profiles of Shigella isolated from foodborne shigellosis of Rio Grande do Sul State, Brazil.

$\mathrm{M}=$ Ladder (1kp), $1=S$. dysenteriae (profile SH3), 2 = S. flexneri (profile SH1), 3= S. sonnei (profile SH2), $4=$ Salmonella Enteritidis 3091/05, 5 =Negative Control

In the present study, the PCR-ribotyping was able to differentiate Shigella species involved in foodborne shigellosis from S. Enteritidis 3091/05. This Salmonella strain presented
SH3 (Fig. 1). Profile SH1 was composed by 116 S. flexneri isolates, and the banding pattern was constituted of two bands (480 and 570bp). Profile SH2 was composed by 35 S. sonnei isolates, presenting a banding pattern of three bands $(350,480$, and 570bp). The profile SH3 contained the S. dysinteriae isolate, presenting a banding pattern of two bands (570, and $700 \mathrm{bp}$ ), but their molecular weights were not the same as of SH1. A band of about 570bp was detected in all Shigella isolates. 
Considering the difficulty to differentiate Salmonella from Shigella by conventional methods, the PCR-ribotyping method used in this study has proven to be suitable for the routine investigation of foodborne outbreaks in RS. Furthermore, the Paula, C.M.D. et al.

species and subspecies levels $(11,20,21)$. PCR-ribotyping has some advantages when compared to other molecular methods, mainly because it is not time-consuming and inexpensive. For example, many reports have used PFGE for typing Shigella because it is very discriminatory and considered the "Gold Standard" for typing microorganisms $(15,26,36)$, but this technique is cumbersome and expensive, hampering its implementation in public health laboratories.

The PCR-ribotyping banding patterns of ten isolates that could not be identified to species level, listed as Shigella spp, were similar to those presented by $S$. sonnei $(\mathrm{n}=2)$ and $S$. flexneri $(n=8)$, suggesting that the ten isolates belonged to these two species. Serology experiments confirmed these results.

The results of this study indicate that the several Shigella strains involved in different Shigellosis outbreaks present the same PCR-ribotyping banding pattern and also the same resistance profile, suggesting that closely related strains may have been the causative agent of the outbreaks. According to Navia and Gascón (26), most often the cases or outbreaks of shigellosis occur due to the clonally propagation of one or a few strains.

It should be noted that PCR-rybotyping resulted in lower number of banding patterns that did the antibiotic resistance testing. Even though antimicrobial resistance in microorganisms could be mediated by plasmids or other transmissible DNA elements, not modifying chromosomal DNA, other molecular typing methods are required to assure the clonal relationship of the Shigella strains.

\section{CONCLUSION}

Several Shigella strains demonstrated similar PCRrybotyping banding patterns and also antibiotic resistance profile, suggesting that closely related strains were responsible for the studied foodborne shigellosis outbreaks occurred in the amplification of the intergenic spacer sequences using rRNA genes is well known as a good tool for typing bacteria (10). These spacer regions demonstrate extensive sequence and length variation that can be used to type bacteria at the genus, Antimicrobial resistance and PCR-Ribotyping of Shigella

State of Rio Grande do Sul. PCR-rybotyping was able to correctly differentiate species of Shigella, demonstrating to be useful for foodborne outbreaks investigation.

\section{ACKNOWLEDGEMENTS}

We would like to express our sincere thanks to the staff of Central Laboratory of Rio Grande do Sul (FEPPS/IPB/LACEN/RS) by providing the samples, especially to Solange Mendes Longaray and Jane Mari Correa Both, of the Food Section, and to Silvia da Silva Rios, of the Bacteriology Section.

\section{REFERENCES}

1. Andrews, W.H.; Flowers, R.S.; Silliker, J.; Bailey J.S. (2001). Salmonella. In: Downes, F.P., Ito, K. (eds). Compendium of methods for the microbiological examination of foods, 4th ed. American Public Health Association. Washington, D.C. p. 357-380.

2. Brasil (2001). Resolução RDC 12 de 02 de janeiro de 2001. Regulamento técnico princípios gerais para o estabelecimento de critérios e padrões microbiológicos para alimentos. Diário Oficial da República Federativa do Brasil, Brasília, 02 de jan. 2001. Seção 1. Available at: http://www.anvisa.gov.br

3. Brasil (2005). Ministério da Saúde. Agência Nacional de Vigilância Sanitária. Lançado projeto para prevenir resistência aos antibióticos. Notícias da Anvisa: Diário e Mensal, Brasília, 22 jun.

Available at: http://www.anvisa.gov.br/divulga/noticias/2005/220705.htm Accessed 17 May 2007.

4. Carmo, G.M.I.; Oliveira, A.A.; Dimech, C. P.; Santos, D.A. dos; Almeida, M.G. de; Berto, L.H.; Alves, R.M.S.; Carmo, E.H. (2005). Vigilância epidemiológica das doenças transmitidas por alimentos no Brasil, 1999-2004. Boletim eletrônico epidemiológico, Brasília. Available

http://portal.saude.gov.br/portal/arquivos/pdf/bol_epi_6_2005_corrigido. pdf

5. Centers for Disease Control and Prevention. (2006). Shigella Surveillance: Annual Summary, 2005. Atlanta, Georgia: US Department of Health and Human Services. Available at: http://www.cdc.gov/ncidod/DBMD/phlisdata/shigtab/2005/ShigellaIntrod uction2005.pdf. 
6. Centers for Disease Control and Prevention. (2008). National Antimicrobial Resistance Monitoring System for Enteric Bacteria (NARMS): Human Isolates Final Report, 2005. Department of Health and Human Services, CDC.

Paula, C.M.D. et al.

sonnei gastroenteritis in Northeastern Taiwan. Pediatr Infect Dis J. 25, 92-4.

9. Coimbra, R.S.; Nicastro, G.; Grimont, P.A.D.; Grimon, F. (2001). Computer identification of Shigella species by rRNA gene restriction patterns. Res. Microbiol. 152, 47-55.

10. De Cesare, A.; Manfreda, G.; Dambaugh, T.R.; Guerzoni, M.E.; Franchini, A. (2001). Automated ribotyping and random amplified polymorphic DNA analysis for molecular typing of Salmonella Enteritidis and Salmonella Typhimurium strains isolated in Italy. J. Appl. Microbiol. 91, 780-785.

11. Dolzani, L.; Tonin, E.; Lagatolla, C.; Prandin, L.; Monti-Bragadin, C. (1995). Identification of Acinetobacter isolates in the A. calcoaceticus-A. baumannii complex by restriction analysis of the 16S-23S rRNA intergenic spacer sequences. J. Clin. Microbiol. 33, 1108-1113.

12. Dromigny, J.A.; Macondob, E.A.; Behr, A.J.; Siby, T.; Claude, JD. PG. (2004). The distribution and antibiotic susceptibility of Shigella isolates in Dakar, Senegal (2000-2002). Int. J. of Antimicrobial. Agents. Amsterdam, Vol. 24, pg. 109-110, 2004

13. Dubois,V.; Parizano, MP.; Arpin, C.; Coulange, L.; Bezian, MC.; Quentin, C. (2007). High Genetic Stability of Integrons in Clinical Isolates of Shigella spp. of Worldwide Origin. . Antimicrob. Agents Chemoth. 51 (4), 1333-1340.

14. Food and Drug Administration (FDA). (2001). Bacteriological analytical manual. 8th Ed. Arlington: AOAC International, Available at: http://www.cfsan.fda.gov/ ebam/bam.> Accessed 19 Jun 2007.

15. Flórez, A.J.; Pérez-Roth, E.; González-Linares, S.; Méndez-Álvarez, S. (2005). Outbreak of Shigella sonnei in a rural hotel in La Gomera, Canary Islands, Spain. Int. Microbiol. 8, 133-136.

16. Fullá, N.; Prado, V.; Durán, C.; Lagos, R.; Levine, M. M. et al. (2005). Surveillance for antimicrobial resistance profiles among Shigella species isolated from a semirural community in the northern administrative area of Santiago, Chile. Am. J. Trop. Med. Hyg. 72 (6), 851-854.

17. Haimovich, B.; Venkatesan, M.M. (2006). Shigella and Salmonella: death as a means of survival. Microbes and Infection. 8, 568-577.

18. Haukka, K.; Siitonen, A. (2008). Emerging resistance to newer antimicrobial agents among Shigella isolated from Finnish foreign travelers. Epidemiol. Infect. 136, 476-482.

19. Jamil, M.; Bashir, S.; Mohsin, M.; Tariq, A.; Bashir, A.; Haque, A.; Sarwar, Y.; Ali, A.; Haque, A. (2007). Differentiation of common gram negative pathogens by PCR-Ribotyping. Pak. J. Med. Sci. 23 (2), 233237.

20. Jensen, M.A.; Webster, J.A.; Straus, N. (1993). Rapid identification of bacteria on the basis of polymerase chain reaction-amplified ribosomal DNA spacer polymorphisms. Appl. Environ. Microbiol. 59, 945-952.
7. Clinical and Laboratory Standards Institute. Performance for Antimicrobial Susceptibility testing; Seventeenth Informational Supplement. (2007). CLSI document M100-S17. Pennsylvania, USA.

8. Chuang, Y.Y.; Huang, Y.C.; Lin, S.Y. (2006). Outbreak of Shigella
21. Jensen, M.A.; Hubner, R.J. (1996). Use of homoduplex ribossomal DNA spacer amplification products and heteroduplex cross-hibridization products in the identification of Salmonella serovars. Appl. Environ. Microbiol. 62, 2741-2746.

22. Kotloff, K.L.; Winickoff, J.P.; Ivanoff, B.; Clemens, J.D.; Swerdlow, D.L.; Sansonetti, P.J.; Adak, G.K.; Levine, M.M. (1999). Global burden of Shigella infections: implications for vaccine development and implementation of control strategies. Bull. World Health Organ. 77, 651666.

23. Kuo, CY.; Su LH., Perera, J.; Carlos, C.; Tan, B.H,; Kumarasinghe, G.; So, T.; Van, P.H.; Chongthaleong, A.; Song, JH.; Chiu, CH. (2008). Antimicrobial susceptibility of Shigella isolates in eight Asian countries, 2001-2004. J. Microbiol. Immunol. Infect. 41,107-111.

24. Lampel, K.A. (2001). Shigella. In: Downes, F.P., Ito, K. (eds). Compendium of methods for the microbiological examination of foods, 4th ed. American Public Health Association. Washington, D.C. p. 381385.

25. Morales, A.J.R.; Rodriguez, C.N.; Garcia, A.; Pastran, B.; Meijomil, P. (2005). Salmonella and Shigella Antimicrobial Resistance Patterns in a General Hospital of Caracas, Venezuela 1997-2003. Int. J. of Antimicrobial Agents. 67-67.

26. Navia, M.M.; Gascón. V.J. (2005). Genetic diversity of Shigella species from different intercontinental sources. Infect. Genet. Evol . 5, 349-353, 2005.

27. Nastasi, A.; Mammina, C. (1995). Epidemiological evaluation by PCR ribotyping of sporadic and outbreak-associated strains of Salmonella enterica serotype Typhimurium. Res. Microbiol. 146 (1), 99-106.

28. Oliveira, F.A. de; Frazzon, A.P.; Brandelli, A.; Tondo, E.C. (2007). Use of PCR-ribotyping, RAPD, and antimicrobial resistance for typing of Salmonella Enteritidis involved in food-borne outbreaks in Southern Brazil. J. Infect. Develop. Country. 1, 170-176.

29. Oliveira, F.A. de; Geimba, M.P.; Brandelli, A.; Silva, W.P.; Pasquali, G.; Tondo, E. C. (2009). Clonal relationship among Salmonella enterica serovar Enteritidis. Food Control. v. 20, p. 606-610.

30. Orrett, F.A. (2008). Prevalence of Shigella serogroups and their antimicrobial resistance patterns in southern Trinidad. J Health Popul Nutr. 26 (4), 456-462.

31. Osorio, M.; Bray, M.D.; Walker, R.I. (2007). Vaccine potential for inactivated shigellae. Vaccine. 25, 1581-1592.

32. Parsot, C. (2005). Shigella spp. and enteroinvasive Escherichia coli pathogenicity factors. FEMS Microbiol. Lett. 252, 11-18.

33. Pazhani, G.P.; Ramamurthy, T.; Mitra, U.; Bhattacharya, S. K.; Niyogi S. K. (2005), Species diversity and antimicrobial resistance of Shigella spp. isolated between 2001 and 2004 from hospitalized children with 
diarrhoea in Kolkata (Calcutta), India. Epidemiol. Infect. 133, 1089-1095

34. Peirano, G.; Souza, F.S.; Rodrigues, D.P. (2006). Frequency of serovars and antimicrobial resistance in Shigella spp. from Brazil. Mem. Inst. Oswaldo Cruz. 101, 245-250.

Paula, C.M.D. et al.

bacillary dysentery cases in Southeast Brazil. Braz. J. Med. Biol. Res.

36. Ranjbar, R.; Mammina, C.; Pourshafie, M.R.; Soltan-Dallal, M.M. (2008). Characterization of endemic Shigella boydii strains isolated in Iran by serotyping, antimicrobial resistance, plasmid profile, ribotyping and pulsed-field gel electrophoresis. BMC Research Notes 2008, 1:74.

37. Ribeiro, R.V. (2000). Shigella: aspectos gerais, clínicos e epidemiológicos. Superintendência de Controle de Zoonoses, Vigilância e Fiscalização Sanitária / SCZ. Boletim de Divulgação Técnica e Científica. Secretaria Municipal de Saúde SMS. Rio de Janeiro. Available at: <http://www.ccs.saude.gov.br/visa/publicacoes/arquivos/bol7.pdf>. Accessed 09 March 2007.

38. Savadkoohi, R.B.; Kacho A.M. (2007). Prevalence of Shigella Species and Their Antimicrobial Resistance Patterns at Amirkola Children's Hospital, North of Iran. Iran J. Ped. 17 (2), 118-122.

39. Sidrim, J.J.C.; Moreira, J.L.B.; Paixão, G.C.; Lima, S.B.; Filho, R.E.M.; Rocha, M.F.G.; Lima, A.Â.M. (1998). Multirresistência a antimicrobianos mediada por plasmídios R em cepas de Shigella flexneri isoladas no nordeste do Brasil. Rev. Soc. Brasil. Med. Trop. 31 (3), 263270 .

40. Silva, T.; Nogueira, P.A.; Magalhães, G.F.; Grava, A.F.; Silva, L.H.P. da;
35. Penatti, M.P.A.; Hollanda, L.M.; Nakazato, G.; Campos, T.A.; Lancellotti, M.; Angellini, M.; Brocchi, M.; Rocha, M.M.M.; Silveira, W.D. da. (2007). Epidemiological characterization of resistance and PCR typing of Shigella flexneri and Shigella sonnei strains isolated from Antimicrobial resistance and PCR-Ribotyping of Shigella

Orlandi, P.P. (2008). Characterization of Shigella spp. by antimicrobial resistance and PCR detection of ipa genes in an infantile population from Porto Velho (Western Amazon region), Brazil. Mem. Inst. Oswaldo Cruz. 103(7), 731-733.

41. Sivapalasingam, S.; Nelson, J.M.; Joyce, K.; Hoekstra, A.M.; F.J.; Mintz, E.D. (2006). High prevalence of antimicrobial resistance among Shigella isolates in the United States tested by the national antimicrobial resistance monitoring system from 1999 to 2002. Antimicrob. Agents Chemoth. 50 (1), 49-54.

42. Tondo, E.C.; Guimarães, M.C.M.; Henriques, J.A.P.; Ayub, M.A.Z. (2000). Assessing and analysing contamination of dairy products processing plant by Staphylococcus aureus using antibiotic resistance and PFGE. Can. J. Microbiol. 46, 1108-1114.

43. Warren, B.R.; Parish, M.E.; Schneider, K.R. (2006). Shigella as a foodborne pathogen and current methods for detection in food. Crit. Rev. Food Scien. Nutrit., 46, 551-567.

44. World Health Organization (WHO) (2005). Guidelines for the control of Shigellosis, including epidemics due to Shigella dysenteriae type 1 . Available at: http://www.who.int/vaccine research/documents/Guidelines _Shigellosis.pdf>. Accessed 24 May 2007. 
